\title{
Professores de matemática em formação inicial elaborando uma situação desencadeadora de aprendizagem no Clube de Matemática
}

\author{
Cezar Augusto Ferreira \\ Maria Marta da Silva \\ Wellington Lima Cedro
}

\begin{abstract}
Resumo: Neste artigo discute-se o potencial do Clube de Matemática como lócus de aprendizagem da docência, tendo o planejamento compartilhado de tarefas de ensino como organizador da atividade de professores de Matemática em formação inicial. Nesse viés o objetivo desse artigo é investigar as contribuições do processo de elaboração de uma Situação Desencadeadora da Aprendizagem (SDA) para a aprendizagem da docência de professores que participam do Clube de Matemática. A SDA foi desenvolvida, com base em uma história virtual na forma de uma história em quadrinhos intitulada "Os Agnuns". A HQ abordava os nexos relacionados ao sistema de numeração. $O$ experimento formativo foi adotado como metodologia de pesquisa. Os resultados demonstraram uma mudança de sentidos em relação à formação docente que esteve todo 0 tempo sustentada com base na intencionalidade e organização de ações no Clube. Também houve indícios da constituição da atividade principal desses professores em formação, salientando o quão é relevante a apropriação conceitual permitida nesse espaço formativo peculiar.
\end{abstract}

Palavras-chave: Formação inicial. Situação desencadeadora da aprendizagem. Clube de matemática.

Cezar Augusto Ferreira Mestrado em Educação em Ciências e Matemática pela Universidade Federal de Goiás (2019). Professor da Escola municipal Leopoldo Moreira (2019), São Simão, Goiás, Brasil.

http://orcid.org/0000-0001-9624-6037 $\bowtie$ cezarferreiramat@gmail.com

Maria Marta da Silva Doutora em Educação em Ciências e Matemática pela Universidade Federal de Goiás (2018). Professora da Universidade

Estadual de Goiás (2002), Quirinópolis, Goiás, Brasil.

http://orcid.org/0000-0003-3717-1439

$\triangle$ profmariamarta@hotmail.com

Wellington Lima Cedro Doutor em Educação pela Universidade de São Paulo (2008). Professor da Universidade Federal de Goiás (2005), Goiânia, Goiás, Brasil.

http://orcid.org/0000-0002-3578-0743 $\triangle$ wcedro@ufg.br

Recebido em 15/04/2021 Aceito em 19/05/2021 Publicado em 26/07/2021

\section{Preservice Mathematics teachers elaborating tasks in the Mathematics Club}

Abstract: This article discusses the potential of the Mathematics Club as a locus of teacher education, having the shared planning of teaching tasks as the organizer of the activity of mathematics teachers in initial training. The objective of this article is to investigate the contributions of the process of design tasks in the Mathematics Club. the task was developed, based on a virtual story in the form of a comic book entitled "The Agunns". The HQ addressed the nexuses related to the numbering system. The formative experiment was adopted as a research methodology. The results showed a change in meanings in relation to teacher training, which was sustained all the time based on the intentionality and organization of actions in the Club. There was also evidence of the constitution of the principal activity of these teachers in training, highlighting how relevant the conceptual appropriation allowed in this peculiar formative space.

Keywords: Preservice teacher education. Tasks. Mathematics club.

\section{Profesores de matemáticas en formación inicial preparando una tarea en el Club de las Matemáticas}

Resumen: En este artículo se analiza el potencial del Club de Matemáticas como locus de enseñanza aprendizaje, teniendo la planificación compartida de las tareas docentes como organizador de la actividad de los profesores de matemáticas en la formación inicial. En esta perspectiva, el objetivo de este artículo es investigar los aportes del proceso de elaboración de una tarea para la enseñanza del aprendizaje de los docentes que participan en el Club de Matemáticas. La tarea se desarrolló a partir de una historia virtual en forma de cómic titulado "The Aguns". La tarea abordó los nexos relacionados con el sistema de numeración. El experimento formativo se adoptó como metodología de investigación. Los resultados 
mostraron un cambio de significados en relación a la formación del profesorado, que se sostuvo todo el tiempo en base a la intencionalidad y organización de las acciones en el Club. También se evidenció la constitución de la actividad principal de estos docentes en formación, destacando la relevancia de la apropiación conceptual permitida en este peculiar espacio formativo.

Palabras clave: Formación inicial. Tareas. Club de las matemáticas.

\section{Introdução}

Libâneo (1999, p. 260) considera que "as transformações das práticas docentes só se efetivam na medida em que o professor amplia sua consciência sobre a própria prática, a da sala de aula e a da escola como um todo, o que pressupõe conhecimentos teóricos e críticos sobre a realidade". Entretanto, na contramão do dito pelo autor, o que se percebe no sistema de ensino brasileiro é a exclusão social, desorganização e mau funcionamento da escola e a desvalorização do professor, fatores estes que implicam diretamente na qualidade da sua principal atividade - a organização do ensino. Rigon, Asbahr e Moretti $(2010$, p. 25) salientam que "[...] cabe ao professor organizar o ensino, tendo em vista que os conhecimentos elaborados historicamente pela humanidade possam ser apropriados pelos indivíduos". Dessa forma, o professor contribuirá de forma a promover um ensino voltado para esse fim criando novas formas de ensino e aprendizagem.

Nesse viés, além de saber no que se constitui a sua atividade o professor deve entender que a importância do seu trabalho depende da compreensão de que a organização do ensino é o fio condutor para realizá-lo e que só por meio dela é que se faz possível a sua atividade principal. Concernente a essa realidade é importante ressaltar que a formação docente desse sujeito é 0 alicerce para a constituição de um indivíduo capaz de se apropriar e produzir a própria cultura.

Ao elencar a formação de professores como um alicerce para a constituição da prática educativa cabe ressaltar que o professor de Matemática deve estar imerso em um ambiente capaz de oferecer a ele dimensões necessárias para uma formação pautada no ensino organizado e intencional. Segundo Moura (1996) quando se eleva a dimensão da formação do professor é necessário também elevar a formação do aluno, como dimensão derivada do trabalho do professor, sendo que as duas não devem ser vistas como dissociadas.

Conexo a isso e, pensando no papel do professor e do aluno no processo de ensino e aprendizagem, bem como nas complexidades da prática docente, foi criado um espaço direcionado à formação de professores de Matemática, inicial e continuada, embasado nos pressupostos defendidos pela Teoria Histórico-Cultural de Vygotsky, na Teoria da Atividade de Leontiev e na proposta teórico-metodológica da Atividade Orientadora de Ensino de Moura (1996, 
2010). Esse espaço conhecido como Clube de Matemática (CluMat), surgido em 1999 na Faculdade de Educação da Universidade de São Paulo sob a coordenação do professor Manoel Oriosvaldo de Moura, visa contribuir para a formação de professores que ensinam matemática assim como para a aprendizagem da Matemática escolar permitindo aos participantes um olhar diferenciado sobre a atividade pedagógica do professor (LOPES, 2009; CEDRO, 2015; OLIVEIRA e CEDRO, 2015).

Portanto, o Clube de Matemática é um espaço de organização e compartilhamento de ações direcionadas a despertar nos sujeitos imersos nesse espaço formativo o surgimento de motivos para a apropriação dos conceitos matemáticos. Com base nesses pressupostos o CluMat UEG - Quirinópolis foi eleito como contexto empírico para a investigação aqui relatada (FERREIRA, 2019).

Deste modo, esse artigo aborda o projeto Clube de Matemática (CluMat - UEG Quirinópolis) da Universidade Estadual de Goiás, Campus Sudoeste Sede Quirinópolis. Tal espaço tem voltado seu olhar para as relações existentes na aprendizagem da docência de professores que participam do Clube de Matemática e a interconexão desse processo com o ensino de conceitos matemáticos na educação básica.

Dentre diversas especificidades do CluMat - UEG (surgido em 2017) está a integralização de parte da carga horária das atividades do estágio curricular supervisionado do curso de Matemática ao mesmo. Participam do CluMat estagiários dos cursos de Matemática, História e Pedagogia, os quais desenvolvem tarefas de ensino com os educandos do Ensino Fundamental I e II de escolas públicas do município sede do projeto. Entre suas principais ações temos: planejamento coletivo das ações de intervenção pedagógica, desenvolvimento de atividades de ensino nas escolas parceiras e avaliação da díade planejamento- desenvolvimento.

Nessa perspectiva, o CluMat - UEG traz outra visão para a formação de professores, pois faz com que a formação inicial seja pensada de forma mais articulada e, ao mesmo tempo, possibilita a melhoria dos processos de ensino e aprendizagem de Matemática na Educação Básica, buscando promover um diálogo entre escola e universidade na formação do professor de Matemática.

A pergunta norteadora é: quais as contribuições do processo de elaboração de uma Situação Desencadeadora da Aprendizagem para a aprendizagem da docência de professores que participam do Clube de Matemática? Conexo à questão problematizadora objetiva-se 
investigar as contribuições do processo de elaboração de uma Situação Desencadeadora da Aprendizagem para a docência de professores que participam do Clube de Matemática.

Na busca do entendimento de qual foi o caminho para o alcance do objetivo e de respostas à questão central optou-se por primeiramente expor o que seria a situação desencadeadora de aprendizagem e, sequencialmente, apresentou-se o contexto empírico da pesquisa: o Clube de Matemática. Logo tem-se o caminho investigativo da pesquisa que deu surgimento a esse artigo, seguido da análise de dados; por último, as considerações finais.

\section{Situação Desencadeadora da Aprendizagem (SDA)}

Há claramente necessidade de se trabalhar os conceitos em seu estágio mais avançado: a sua estrutura atual vem ao encontro das necessidades contemporâneas da sociedade, mas não se pode desconsiderar o caminho lógico traçado historicamente pelo conceito. Negligenciar ao estudante 0 contato com estas relações pode privá-lo de realmente atribuir significado às suas ações. Saber operar com algoritmos e regras de resolução é muito superficial se comparado àquilo que se pode aprender quando se conhece os nexos internos de um conceito. Prender o aluno aos elementos perceptíveis de um conceito, chamados também de nexos externos do mesmo, ou seja, aqueles elementos formais relativos à linguagem é equivalente a impedi-lo de se colocar no movimento de pensamento que o levaria a construir conhecimento teórico.

Portanto, é importante destacar que a maneira como o ensino nas escolas está organizado busca com frequência atrelar o conhecimento científico à experiência, mas esta é uma fundamentação que limita o pensamento, pois "ao unir os objetos e os fenômenos com termos aparentes, ele não consegue estabelecer as reais inter-relações que constituem o sistema integral, universal e transitório, dos fenômenos e dos objetos" (ROSA; MORAES e CEDRO, 2010, p.78).

Portanto, apresentar conhecimento científico ao aluno é demonstrar a fluência da realidade objetiva, bem como a importância da busca por explicar e interpretar esta realidade. Segundo Oliveira (2002, p. 52) o conhecimento científico "trabalha com a construção de categorias formalizadas de organização de seus objetos e com processos deliberados de generalização, buscando leis e princípios universais, estruturados em sistemas teóricos com clara articulação interna". Conhecer as etapas da construção do conhecimento pode desencadear o pensamento na busca por novas estratégias que tragam respostas às novas necessidades do agora (que ainda não foram supridas), bem como das que hão de vir, pois a realidade muda, bem como mudam as 
linguagens dos conceitos (nexos externos) - guardando apenas aquilo que the é intrínseco, a sua essência, os seus nexos internos ou conceituais.

Essa realidade demanda dos professores a responsabilidade de ensinar os seus alunos a transcender, abstrair, generalizar. Assim, "ao ancorar o ensino de Matemática na memorização e na repetição, a perspectiva empirista acaba por limitar o processo de pensamento dos estudantes e, consequentemente, o desenvolvimento humano" (ROSA, MORAES e CEDRO, 2010, p. 137). É preciso estimular os alunos a pensar sobre a solução, a desenvolver estratégias, a desprender-se do ensino pautado no aparente e empírico. Afinal, "o conceito não é simplesmente um conjunto de conexões associativas que se assimila com a ajuda da memória, não é um hábito mental automático, mas um autêntico e completo ato do pensamento" (VYGOTSKY, 1993, p. 184).

Frente a essas considerações foram reputadas necessárias ações que se desvinculam de modelos de ensino de conceitos matemáticos baseados exclusivamente nos nexos externos dos mesmos, mas que na contramão disso coloquem os alunos em movimento de pensamento, o qual deve percorrer os caminhos lógicos que o conceito traçou historicamente, abrindo a porta para 0 pensamento teórico. Segundo Davydov (1982, p. 34) "o pensamento teórico é o processo de idealização de um dos aspectos da atividade objetal- prática, a reprodução, que representa as formas universais dos objetos".

Para que isso seja possível na sala de aula, professores em formação devem ter contato com essa possibilidade teórica e alicerçados a ela podem ter condições objetivas para organizar um ensino que realmente conduza à aprendizagem. Ou seja:

[...] oscilando entre momentos de reflexão teórica e ação prática e complementandoos simultaneamente que o professor vai se constituindo como profissional por meio de seu trabalho docente, ou seja, da práxis pedagógica. Podemos dizer então que: se, dentro da perspectiva histórico-cultural, o homem se constitui pelo trabalho, entendendo este como uma atividade humana adequada a um fim e orientada por objetivos, então o professor constitui-se professor pelo seu trabalho - a atividade de ensino - ou seja, o professor constitui-se professor na atividade de ensino. Em particular, ao objetivar a sua necessidade de ensinar e, consequentemente, de organizar o ensino para favorecer a aprendizagem (MORETTI, 2007, p. 101).

A atividade principal do professor é o ensino, portanto, é preciso organizá-lo de forma a não o contemplar como um ensino qualquer, mas sim que conduza o sujeito ao seu desenvolvimento, ou seja, é preciso buscar uma educação que promova o desenvolvimento humano. Assim, CEDRO (2008, p. 59) afirma que "acreditamos nessa forma de organização para possibilitar a todos os indivíduos envolvidos no processo a apropriação dos nexos conceituais que permitam o amplo desenvolvimento da sua condição humana". 
As tarefas de ensino organizadas de acordo com a estrutura teórico-metodológica da AOE em um espaço peculiar, o Clube de Matemática - CluMat UEG Quirinópolis -, podem permitir a aprendizagem do aluno e conduzi-lo ao seu desenvolvimento humano. Estamos entendendo AOE segundo Moura (1996) como uma atividade que promove a interação com os sujeitos mediada por um conteúdo na finalidade de solucionar coletivamente um problema. Essas atividades definem as ações docentes no CluMat, onde todos os sujeitos envolvidos atuam sobre a realidade formativa a que pertencem. CEDRO (2004, p. 47) define o Clube de Matemática como um espaço de aprendizagem, um contexto capaz de "fundamentar uma organização do ensino que possa superar o 'encapsulamento' da aprendizagem escolar ou como o lugar da realização da aprendizagem dos sujeitos orientados pela ação intencional de quem ensina".

A AOE segue uma estrutura calcada no movimento lógico-histórico dos conceitos. Assim, essa proposta leva em consideração a origem do conceito matemático e qual necessidade humana motivou a sua construção. Kopnin (1978, p. 184) explica que "para revelar a essência do objeto é necessário reproduzir o processo histórico real de seu desenvolvimento, mas este é possível somente se conhecemos a essência do objeto". Deste modo, é necessário também conhecer como a humanidade apropriou-se desses conhecimentos. Portanto, o professor ao tomar consciência dos seus objetivos acerca do ensino, colocará em movimento as ações dos sujeitos para que se apropriem do conceito. Em vista disso, Moura et al. (2010, p. 103) pontuam:

\footnotetext{
Essas ações, por sua vez, ao serem desencadeadas, considerarão as condições objetivas para o desenvolvimento da atividade: as condições materiais que permitem a escolha dos recursos metodológicos, os sujeitos cognoscentes a complexidade do conteúdo em estudo e o contexto cultural que emoldura os sujeitos e permite as interações socioafetivas no desenvolvimento das ações que visam ao objetivo da atividade - a apropriação de um certo conteúdo e do modo geral de ação da aprendizagem.
}

Deste modo a AOE tem como uma de suas etapas a Situação Desencadeadora da Aprendizagem que aqui foi realizada com base em uma história virtual que se objetivou no formato de uma HQ. Para Moura et al. (2010, p.105) a SDA pode ser "uma narrativa que proporciona ao estudante envolver-se na solução de um problema como se fosse parte de um coletivo que busca solucioná-lo, tendo como fim a satisfação de uma determinada necessidade, à semelhança do que pode ter acontecido em certo momento histórico da humanidade". A SDA deve conter a origem do conceito a ser estudado para que realizem operações que compõem a aprendizagem dos alunos, formalizando assim o pensamento teórico-científico e permitindo a assimilação da essência do objeto. Ou seja, "trata-se da unidade do histórico e do lógico como premissa para compreender a essência de um objeto, de um conceito, sua estrutura, sua história, seu desenvolvimento" (MOURA 
et al., 2010, p. 104). Essa situação desencadeadora da aprendizagem deve levar os alunos à solução coletiva do problema desencadeador da aprendizagem, mas para isso é necessário que sejam proporcionados momentos que necessitem do compartilhamento de ações situadas na interação social para que num contexto específico cheguem a uma resposta comum. Ao resolverem coletivamente ações compartilhadas, os alunos serão capazes de identificar os objetos e as transformações ocorridas da experiência social para individual, internalizando assim os processos culturais e apropriando-se do conceito que está sendo estudado.

Portanto, para que o professor consiga mediar o conhecimento para os seus alunos, levando-os à apropriação conceitual, um caminho que pode ser escolhido como facilitador no processo de organização de ensino é a abordagem lógico-histórica dos conceitos matemáticos. Neste viés temos a proposta teórico-metodológica das Atividades Orientadoras de Ensino com foco principal na Situação Desencadeadora de Aprendizagem, valendo-se das histórias em quadrinhos como forma de apresentação.

\section{CluMat UEG Quirinópolis: espaço de constituição da pesquisa}

O CluMat UEG - Quirinópolis busca promover a atividade como aspecto essencial no desenvolvimento do indivíduo, visto que ocorre de maneira processual e conexa às dimensões pessoais e coletivas dos sujeitos envolvidos. Deste modo, realizar o processo de formação de professores e a aprendizagem de alunos do ensino básico no Clube de Matemática resulta em compreender os aspectos que compõem a ação educativa como totalidade.

O Clube de Matemática é entendido no âmbito da Universidade Estadual de Goiás (Campus Quirinópolis) como um espaço de aprendizagem, um ambiente permeado pela análise crítica, descoberta e prática social, no qual o sujeito participante concebe situações que envolvem processos interindividuais e intraindividuais que lhes dão possibilidades de desenvolvimento. Entendemo-lo como um ambiente para o desenvolvimento de atividades formativo-educativas que possibilitam a discussão dos mais variados aspectos concernentes à aprendizagem da docência em Matemática e ao ensino da Matemática escola, tendo como objetivo criar condições que permitam aos participantes estabelecer relações entre as componentes abstratas e concretas dos conteúdos matemáticos (SILVA e SOUZA, 2019, p. 51-2).

O CluMat UEG - Quirinópolis foi criado com base em um projeto de pesquisa submetido à PRP/UEG com vigência 2017/2021 pela professora Maria Marta da Silva. Desde então, o objetivo do CluMat da UEG Quirinópolis é possibilitar aos licenciandos o desenvolvimento da 
aprendizagem da docência em Matemática conexa à compreensão do processo de aprendizagem dos conceitos matemáticos ensinados na educação básica.

Espera-se que uma das principais contribuições científicas do CluMat UEG - Quirinópolis seja a criação de ambiente que possibilite o desenvolvimento da docência em Matemática num universo que conjugue não somente os conhecimentos ditos matemáticos, mas também na interdependência com os didático-pedagógico-metodológicos, colaborando para 0 estabelecimento de um espaço para discussão e reflexão sobre os processos de ensino e aprendizagem da Matemática.

Nesta perspectiva, esse CluMat pretende se tornar "um ambiente para o desenvolvimento de atividades educativas que possibilitem a discussão dos mais variados aspectos dentro do meio educacional" (CEDRO, 2004, p.52) e também um espaço de aprendizagem dos professores (CEDRO, 2004). Portanto, é notória a preocupação com a formação dos professores que ensinam Matemática e também com o processo de ensino e aprendizagem na educação básica.

Espera-se que os sujeitos envolvidos sejam capazes de criar e desenvolver tarefas de estudo pautadas nos pressupostos teórico-metodológicos das Atividades Orientadoras de Ensino a fim de promover o ensino de conceitos matemáticos para a educação básica. Tais atividades serão tidas no universo do CluMat como elemento organizador da atividade pedagógica e também formadora da aprendizagem do aluno. Nesse viés o objetivo do professor é mediar o conhecimento historicamente acumulado levando à formação do pensamento teórico-científico.

O CluMat UEG - Quirinópolis interconexa dois contextos díspares, mas interdependentes - formação de professores que ensinam Matemática e aprendizagem da Matemática escolar. No que diz respeito à formação de professores esse CluMat atende estagiários e acadêmicos do curso de Matemática, História e Pedagogia, além de professores da rede municipal e estadual de ensino. Em relação ao processo de aprendizagem escolar contempla alunos das escolas de rede municipal e estadual de ensino (EF I e II) do município de Quirinópolis, Inaciolância e Iltarumã (todos pertencentes ao Estado de Goiás).

É importante salientar que o CluMat UEG - Quirinópolis não se restringe aos muros da Universidade, vez que ora os alunos se deslocam até a Universidade e, outras vezes, o Clube vai até as escolas dos municípios participantes do projeto. As ações do clube estão organizadas da seguinte maneira (Figura 1): 
Figura 1: Organização das ações do CluMat

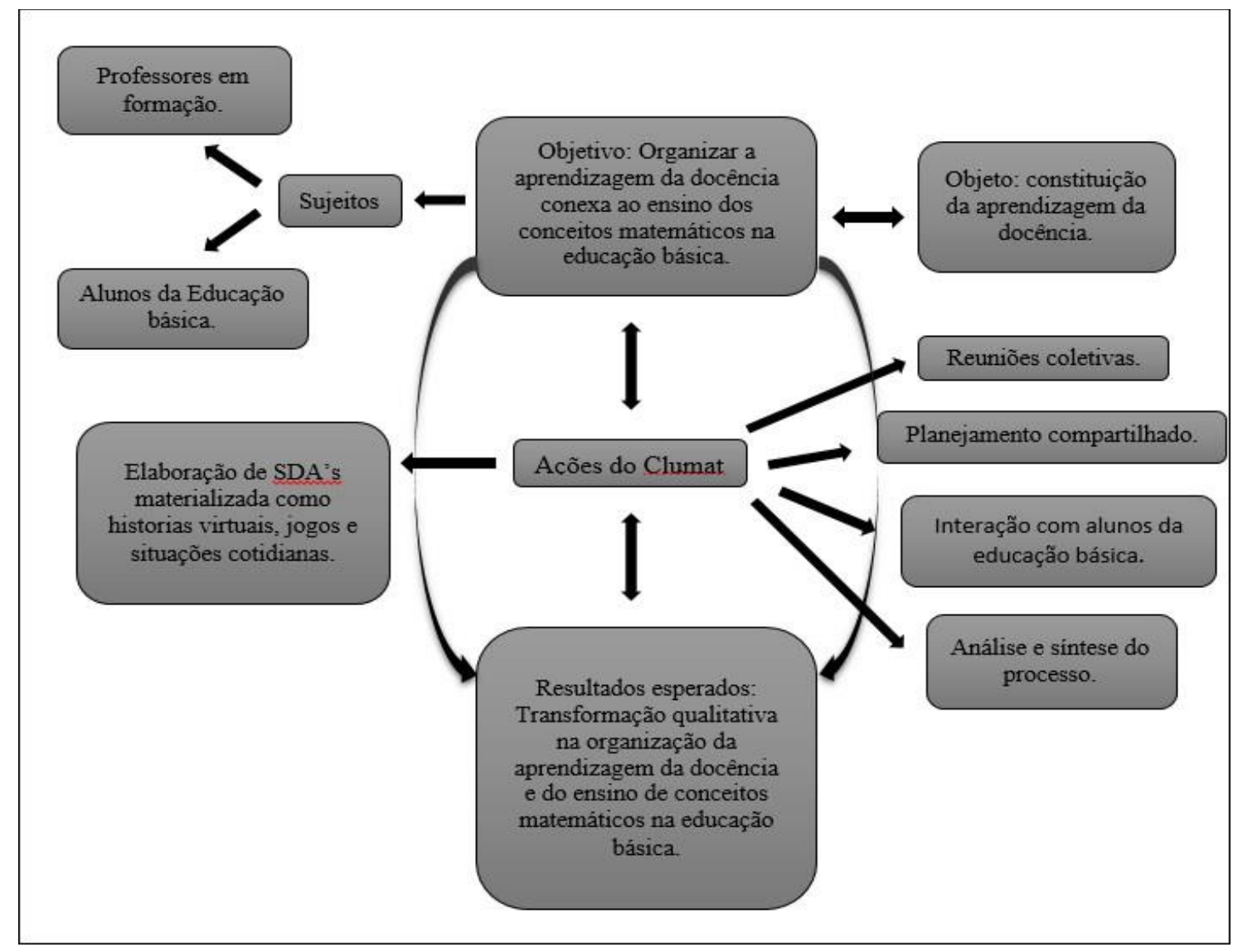

Fonte: Elaborado pelos autores (2019).

Essas ações estão envoltas na perspectiva de desenvolvimento da objetivação da aprendizagem da docência em Matemática e do ensino de Matemática por licenciandos das três licenciaturas envolvidas no projeto. Deste modo, esse CluMat, como os demais, preocupa-se com a aprendizagem no âmbito escolar voltada para o desenvolvimento psíquico dos estudantes das escolas parceiras e a aprendizagem docente, aliada à efetivação da organização do ensino. Desta forma, o CluMat UEG - Quirinópolis planeja atividades de ensino estruturadas de maneira que ofereçam condições para que os alunos se aproximem de determinado conhecimento cientifico (MOURA, 2002), além da preocupação com a busca das particularidades do pensamento teórico que possam se desenvolver durante o planejamento e desenvolvimento das atividades de ensino 
que terão como objetivo a aprendizagem da docência em Matemática e a própria aprendizagem da Matemática escolar pelos alunos da educação básica das escolas participantes do projeto.

\section{Os caminhos investigativos}

Nesta pesquisa foram acompanhados os futuros licenciandos em Matemática durante 0 período de um ano letivo no Clube de Matemática inseridos em um experimento formativo, sendo na concepção de CEDRO (2008, p. 105) " um método de investigação psicológica que permite estudar a essência das relações internas entre os diferentes procedimentos de ensino e o correspondente caráter de desenvolvimento psíquico do indivíduo. Um dos pontos essenciais dessa perspectiva é que ela pressupõe a intervenção ativa do pesquisador nos processos psíquicos que ele estuda".

É importante salientar primeiramente quão árduo e complexo é descrever e analisar todas as ações do CluMat. Por isso, a investigação foi direcionada especialmente a uma unidade didática e a pesquisa como um todo constituiu-se ao longo de um ano (junho de 2017 a junho de 2018). Portanto, os dados apresentados referem-se a esse recorte temporal. Vejamos na Figura abaixo (Figura 2) a estrutura organizativa do experimento formativo realizado com os professores de Matemática em formação:

Figura 2: Constituição do experimento formativo

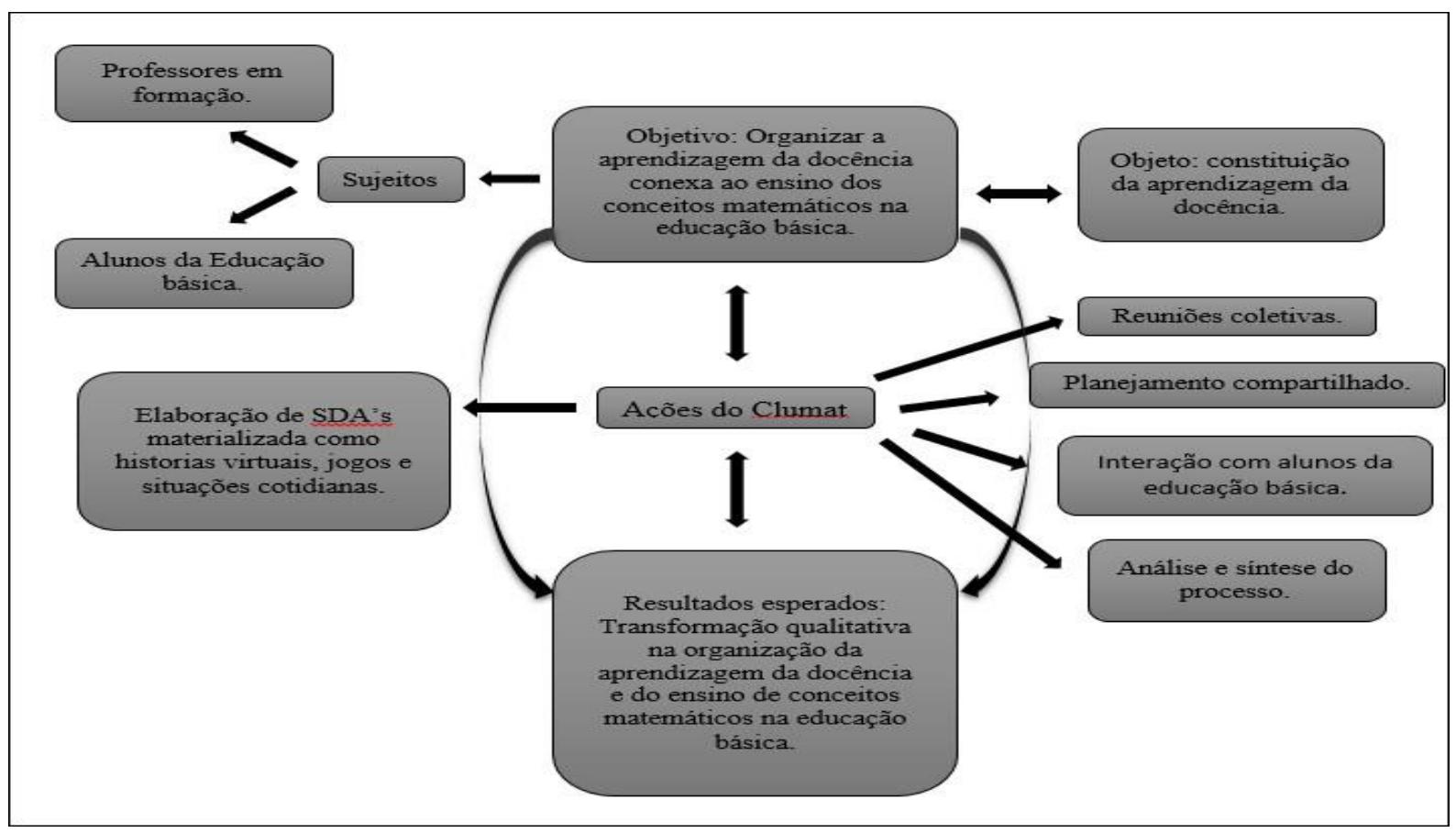

Fonte: Ferreira (2018)

No período selecionado para essa pesquisa tivemos 23 encontros (Quadro 1). Os mesmos 
tiveram a participação da coautora e coordenadora do CluMat UEG - Quirinópolis, do primeiro autor e dos professores em formação inicial.

Quadro 1: Organização dos encontros

\begin{tabular}{|c|c|c|}
\hline Enc. & Datas & Ação \\
\hline 1 & $13 / 05 / 2017$ & \multirow{2}{*}{$\begin{array}{l}\text { Estudo realizado entre os professores coordenadores para a escolha da temática e } \\
\text { ações do encontro. }\end{array}$} \\
\hline 2 & 20/05/2017 & \\
\hline 3 & $27 / 05 / 2017$ & Inicio do estudo com os acadêmicos e a discussão do $1^{\circ}$ texto proposto. \\
\hline 4 & $03 / 06 / 2017$ & $\begin{array}{l}\text { Estudo sobre os pressupostos teóricos da atividade orientadora de ensino e } \\
\text { discussão do } 2^{\circ} \text { texto. }\end{array}$ \\
\hline 5 & $10 / 06 / 2017$ & Divisão dos trabalhos e início da criação do enredo. \\
\hline 6 & $17 / 06 / 2017$ & \multirow{2}{*}{ Criação das primeiras falas e das primeiras cenas. } \\
\hline 7 & $24 / 06 / 2017$ & \\
\hline 8 & 19/08/2017 & \multirow{7}{*}{$\begin{array}{c}\text { Criação e continuação da história, novas falas e constituição do } 1^{\circ} \text { nexo, o nexo } \\
\text { contagem. }\end{array}$} \\
\hline 9 & $26 / 08 / 2017$ & \\
\hline 10 & $02 / 09 / 2017$ & \\
\hline 11 & $16 / 09 / 2017$ & \\
\hline 12 & 23/09/2017 & \\
\hline 13 & $30 / 09 / 2017$ & \\
\hline 14 & $07 / 10 / 2017$ & \\
\hline 15 & $14 / 10 / 2017$ & \multirow{5}{*}{$\begin{array}{c}\text { Criação e continuação da história, novas falas e constituição do } 2^{\circ} \text { nexo, o nexo } \\
\text { medida. }\end{array}$} \\
\hline 16 & $21 / 10 / 2017$ & \\
\hline 17 & $04 / 11 / 2017$ & \\
\hline 18 & $11 / 11 / 2017$ & \\
\hline 19 & $18 / 11 / 2018$ & \\
\hline 20 & $10 / 03 / 2018$ & \multirow{5}{*}{$\begin{array}{c}\text { Criação e continuação da história, novas falas e constituição do } 3^{\circ} \text { nexo, o nexo } \\
\text { unidade de medida. }\end{array}$} \\
\hline 21 & $17 / 03 / 2018$ & \\
\hline 22 & $24 / 03 / 2018$ & \\
\hline 23 & 07/04/2018 & \\
\hline 24 & $14 / 04 / 2018$ & \\
\hline 25 & $19 / 05 / 2018$ & \multirow{2}{*}{ Desenvolvimento da tarefa de estudo nas escolas parceiras. } \\
\hline 26 & 09/06/2018 & \\
\hline 27 & $16 / 06 / 2018$ & $\begin{array}{l}\text { Avaliação da tarefa de estudo desenvolvida nas escolas parceiras e o feedback dos } \\
\text { acadêmicos acerca da participação no experimento. }\end{array}$ \\
\hline 28 & $\begin{array}{l}18 / 06 / 2018 \\
29 / 06 / 2018\end{array}$ & ento de entrevistas com os sujeitos da pesquisa. \\
\hline
\end{tabular}

A coleta de dados contou com o uso dos seguintes instrumentos: entrevistas, registros escritos e gravações em áudio-vídeo de todos os momentos (de planejamento e desenvolvimento), sendo transcritos de forma fiel e íntegra para que seja feita a análise posterior.

Essa pesquisa teve como sujeitos 18 estudantes que integravam e participavam do CluMat, e eram pertencentes ao curso de Licenciatura em Matemática. 


\section{Análise e discussão dos dados}

Compreender a transformação dos professores em formação exigiu a constituição de caminhos para compreender o fenômeno e alcançar o objetivo - investigar as contribuições do processo de elaboração de uma Situação Desencadeadora da Aprendizagem para a aprendizagem da docência de professores que participam do Clube de Matemática - e, dessa forma, conhecer os processos internos para ir além do aparente, desvelando as relações que dão significado à atividade principal do professor, o ensino.

Para compreender um fenômeno dessa complexidade o pesquisador deve exercer um acurado trabalho de análise. Nosso ponto inicial foi o aporte teórico para que, a partir dele, houvesse condições objetivas de construir "um elo entre o desenvolvimento conceitual" (RADFORD, 2011, p.74) do sujeito e a realidade objetiva que tínhamos. Deste modo, foi necessário o cuidado de criar motivos e necessidades nos acadêmicos para que o movimento do pensamento se constituísse e, om base nele, percebéssemos, pouco a pouco, as contribuições do processo de elaboração de uma SDA para a aprendizagem da docência dos professores em formação.

Portanto, optou-se por criar unidades de análise que, segundo Vygotsky (1993, p. 125), é "[...] o resultado da análise que diferencia os elementos, mas goza de todas as propriedades fundamentais características do conjunto constitutivo, sendo uma parte viva e indivisível da totalidade". Percebendo que não seria possível expressar todo o fenômeno procurou-se evidenciar nessas unidades de análise aspectos que representem o todo, ou seja, que carreguem consigo a essência da totalidade.

Tais unidades foram compostas de episódios que, consoante Moura (2004, p. 276) "são a tentativa de construir um modo de analisar as interdependências [...] são aqueles momentos em que fica evidente uma situação de conflito que pode levar à aprendizagem do novo conceito". Ainda segundo o estudioso os episódios foram subdivididos em cenas que podem não apresentar uma linearidade, mas revelar a interdependência entre uma ação formadora e outra, demonstrando assim os momentos em que os acadêmicos se colocam em movimento de pensamento, apropriando-se dos nexos conceituais.

Nessas cenas são identificados os flashes, os quais para SILVA $(2018$, p.149) são "indícios da transformação do pensamento do sujeito acerca de algo que se converte. Compreendidos como indícios observáveis que comprovariam a existência do processo 
decomposição da significação de um sujeito". A seguir, na Figura 3, está evidenciada a estrutura de análise:

Figura 3: Organização da análise dos dados

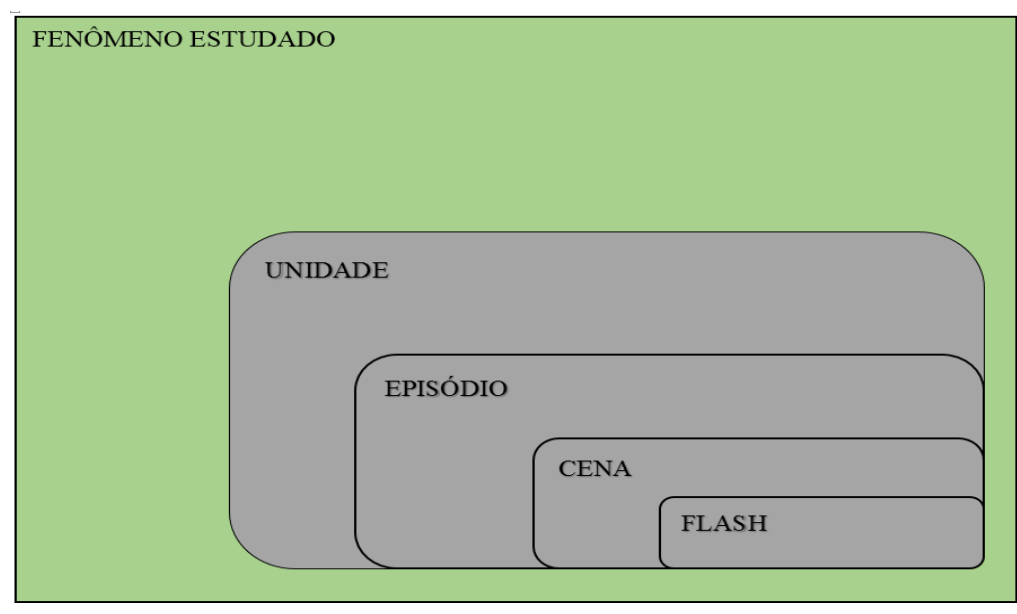

Fonte: Adaptado de SILVA (2018)

$\mathrm{A}$ análise se alicerça fundamentada na interdependência entre o lastro teórico $\mathrm{e}$ os dados da pesquisa. A teoria permitiu identificar os elementos a serem investigados conduzindo os questionamentos a partir de uma perspectiva de atribuição de sentido sobre ofenômeno estudado.

\section{Unidade de análise: A aprendizagem da docência em matemática a partir da elaboração e desenvolvimento de uma SDA}

Essa unidade tem como destaque os indícios do processo de aprendizagem da docência a partir da elaboração e desenvolvimento da SDA. Esse desenvolvimento permite estabelecer relações entre o motivo e o objetivo da atividade. A SDA foi desenvolvida no âmbito do CluMat UEG - Quirinópolis por professores de Matemática em formação. Pensando na melhor forma de apresentar o conceito de números o grupo optou pela história virtual na forma de uma história em quadrinhos intitulada "Os Agnuns".

Para compreender a importância do papel da AOE nesse processo foi necessário entender o conceito de Atividade proposto por Leontiev (1978, p. 68), "por atividade, designamos os 
processos psicologicamente caracterizados por aquilo que o processo, como um todo, se dirige (seu objeto), coincidindo sempre com o objetivo que estimula o sujeito a executar esta atividade, isto é, o motivo". Deste modo, ancorados em tais premissas teóricas foram analisadas o contexto e as ações formativas dos sujeitos dessa pesquisa por meio do desenvolvimento do processo de constituição da sua atividade principal.

Embasado no conceito de atividade de Leontiev, Moura (2002) traz a AOE como instrumento teórico-metodológico, pois a mesma constitui-se num modo geral de organização do ensino em que o seu conteúdo principal é o conhecimento teórico e o seu objeto é a constituição do pensamento teórico no movimento de apropriação do conhecimento. Assim, acredita-se que os professores ao participarem do movimento de elaboração da SDA serão capazes de transformar e transformar-se por meio da relação entre ensino e aprendizagem do conhecimento historicamente acumulado pela humanidade. Diante disso, o sujeito, aqui o professor, ao estar em atividade é capaz de se apropriar dos bens culturais a partir da sua função primordial, a organização do ensino.

\subsection{Episódio: As diversas contribuições da SDA para formação do professor de Matemática}

Neste episódio buscar-se-á dentro dos pressupostos teóricos e metodológicos da AOE a relevância do papel da SDA no processo formativo do professor de Matemática. Para tanto foram selecionadas duas cenas que realçam a importância do CluMat como ambiente peculiar na formação do professor e como a compreensão teórica da AOE também pode contribuir para essa aprendizagem docente. A organização e seleção das cenas se deram na tentativa de permitir a compreensão do movimento dos clubistas durante o projeto no intuito de conhecer indícios de apropriação teórica e prática dos sujeitos de pesquisa acerca das contribuições do CluMat como espaço de aprendizagem da docência:

Cena 1 - As possibilidades de aprender e ensinar a partir da estrutura proposta no CluMat

Constituição da cena: Esta cena é composta de fragmentos de uma entrevista realizada com os professoresem formação no CluMat posteriormente ao desenvolvimento das atividades na escola parceira. Na entrevistafizemos o seguinte questionamento: Quais foram as contribuições do CluMat para seu desenvolvimento enquanto futuro professor? Procuramos aqui as contribuições que o Clube de Matemática da UEG CampusQuirinópolis ofereceu para os professores em formação que participaram da atividade do conceito de números. A cena está localizada no vigésimo oitavo momento do experimento formativo.

Aluno 01: Acredito que as contribuições foram várias, dentre elas posso falar que o fato de você trabalharcom outras pessoas, a interação com os alunos do curso, o fato de você sair daquele método tradicional, ter uma aula mais lúdica a $\mathrm{HQ}$ então transmiti isso e ter uma nova visão pra você elabora ou ensinar conceitos matemáticos usando uma teoria porque até então parecia que dar aula de matemática era algo muito prático que não tinha uma teoria capaz de organizar isso pra mudar. (Flash 1)

Aluno 02: O CluMat contribuiu porque a gente aprende a trabalhar em equipe e o professor sai da mesmicee da 
aula tradicional, aqui aprendemos a trabalhar com ideias e teorias novas, por que você dando uma auladiferente desperta o interesse do aluno, vai sair daquela mesma coisa quadro e giz, não que isso não seja importante mas uma coisa diferente pode ajudar muito.

Aluno 03: Eu acho que a principal contribuição do CluMat está na base teórica que ele dá para a pratica pedagógica da gente, a gente passa as séries todas vendo o professor ali sem a teoria, só na pratica, só sembase teórica, eu acho que principal contribuição foi a fundamentação teórica que o CluMat dá pra gente. (Flash 2)

Aluno 4: Quando ingressei na graduação tive algumas dificuldades em relação ao planejamento das aulas e quando comecei a participar do clube de matemática e conheci novas teorias e metodologias, novas formas de efetivar esse planejamento, nós participamos de um contexto rico em embasamento teórico e metodológico, e esse embasamento proporciona a nos futuros professores uma apropriação de como tem que ser a pratica pedagógica do professor de como ele tem que estruturar seu ensino.

Aluno 5: O clube demonstra para nós que o ensino tem que ser intencional e organizado. (Flash 3)

Aluno 6: Antes de ingressar no clube de matemática eu não tinha essa visão em relação a minha pratica pedagógica, a formação da minha pratica, então o CluMat influenciou nesta questão, me fez compreenderos nexos internos dos conceitos, me ajudou na apropriação dos conceitos matemáticos primeiro para depois estruturar uma maneira de ensinar os alunos, então primeiro você se apropria para depois você mediar 0 ensino. (Flash 4)

Aluno 7: Eu vejo o CluMat como um espaço pra você aprender a dar aula e colocar em prática aquilo que você veria em sala de aula, muitas vezes você vai na faculdade e aprende a fazer plano de aula, você aprendeos conceitos básicos, mas não tem a forma didática, e o CluMat ele auxilia nesta questão de você entrar em movimento na didática, você aprende formas didáticas de ensinar pra sair do método tradicional, então pra esses novos professores que estão sendo formados o CluMat pode contribuir muito na formação do professor, mudando a rotina de ensino.

Aluno 8: Foi importante porque aprendemos a planejar atividades para ensinar matemática sem ser do método tradicional, sem falar somente onde os alunos abrem os livros e resolvem exercícios.

Aluno 9: Então esses planejamentos que fazemos aqui no clube são importantes porque aprendemos uma nova forma de ensinar matemática utilizando situações desencadeadoras da aprendizagem, isso é importante porque levamos para o aluno uma nova visão de ensinar matemática porque os alunos já estãoacostumados em toda aula de matemática ser sempre a mesma coisa, com o CluMat podemos aprender umanova forma de ensinar matemática. (Flash 5)

Para analisar essa cena é preciso entender o Clube de Matemática como espaço de aprendizagem que exige a organização do ensino de Matemática a partir da permissão de condições objetivas para desenvolvimento psíquico dos sujeitos. Observa-se essa vertente no seguinte flash: "Acredito que as contribuições foram várias, dentre elas posso falar que o fato de você trabalhar com outras pessoas, a interação com os alunos do curso, o fato de você sair daquele método tradicional, ter uma aula mais lúdica, ter a $\mathrm{HQ}$, então transmiti isso e ter uma nova visão pra você elabora ou ensinar conceitos matemáticos usando uma teoria porque até então parecia que dar aula de Matemática era algo muito prático que não tinha uma teoria capaz de organizar isso pra mudar" (Flash 1, Cena 1). Assinala-se nesse flash pontos importantes sobre os conhecimentos necessários para que o professor exerça sua atividade, que é o ensino. Deste modo, o Clube assume princípio educativo na formação intelectual dos professores, vez que permite a apropriação dos elementos organizadores do ensino.

Diante disso, Moraes e Moura (2009) ratificam que a atividade de ensino é materializada na SDA, onde as ações são direcionadas para o objetivo principal do professor que é ensinar e 
isso permite que o professor se aproprie dos conhecimentos historicamente acumulados pela humanidade, promovendo então, o processo de humanização a partir do ensino.

Nessa perspectiva o Clube configura-se como espaço de humanização em que a atividade de aprendizagem docente permite que o sujeito aproprie -se dos conhecimentos teóricos e organize suas ações, fazendo com que a aprendizagem aconteça de forma intencional e planejada: "eu acho que a principal contribuição do CluMat está na base teórica que ele dá para a prática pedagógica da gente, a gente passa as séries todas vendo o professor ali sem a teoria, só na prática, sem base teórica, eu acho que a principal contribuição foi a fundamentação teórica que o CluMat dá pra gente" (Flash 2, Cena 1); "o clube demonstra para nós que o ensino tem que ser intencional e organizado" (Flash 3, Cena 1). Davidov e Markova (1987, p. 180) comungam com este pensamento ao defenderem que "o ensino constitui a forma internamente indispensável e geral de desenvolvimento intelectual". Deste modo, ter uma base teórico-metodológica que sustenta a atividade do professor, a qual é efetivada dentro de um ambiente de aprendizagem, permite a partir do trabalho coletivo a efetivação da práxis pedagógica, assim o sujeito ancora suas ações no intuito de compreender o papel da educação e da organização do ensino sobre a atividade do professor e a formação da consciência (MOURA, 2010). Ainda nesse flash percebemos o entendimento pelos sujeitos de que a constituição do trabalho docente deve se sustentar na intencionalidade de suas ações, a qual deve "impactar os sujeitos, proporcionando as alterações no desenvolvimento de suas funções psíquicas e a apropriação de conceitos científicos" (MOURA, 2010, p. 114). Com isso, fundamentados na organização do ensino amparada em ações planejadas de forma intencional, nessas condições, a AOE caracterizou-se como princípio formativo dos professores em formação no decurso dessa investigação.

Nesse processo de organização do ensino o professor realiza a dinâmica do pensamento para compreender a realidade objetiva que o cerca: "Antes de ingressar no Clube de Matemática eu não tinha essa visão em relação a minha prática pedagógica, a formação da minha prática, então o CluMat influenciou nesta questão, me fez compreender os nexos internos dos conceitos, me ajudou na apropriação dos conceitos matemáticos primeiro para depois estruturar uma maneira de ensinar os alunos, então primeiro você se apropria para depois você mediar o ensino" (Flash 4, Cena 1). Kopnin (1978) corrobora com essa discussão ao pontuar que a base do conhecimento dialético (do histórico e do lógico) resolve o problema da correlação entre o pensamento individual e social em seu desenvolvimento intelectual. Isso mostra a necessidade de conhecer o processo de elaboração do conhecimento como resultado da ação humana, para propiciar a atividade de aprendizagem nos sujeitos. Nesse caminho, os flashes nos dão sinais de que os professores em 
formação se preocuparam com o surgimento histórico do conceito, ou seja, para configurar a essência do objeto em estudo é necessário que este estudo abarque o processo lógico-histórico.

Deste modo, é com base no movimento lógico-histórico que se constitui a essência do conceito e as formas de apropriação pela humanidade, ou seja, a AOE se configura para a solução de um problema de aprendizagem em que os sujeitos se apropriam de ações gerais que se tornam a base de orientação nas mais diversas situações que podem ocorrer esse movimento, estando 0 mesmo em concomitância com a realidade humana e suas necessidades (MOURA, 2010).

Nesse movimento de compreender a origem do conceito para a constituição da atividade docente, temos no próximo flash a importância dada à elaboração da SDA no processo de aprendizagem da docência dentro do contexto do CluMat: "Então esses planejamentos que fazemos aqui no Clube são importantes porque aprendemos uma nova forma de ensinar Matemática utilizando situações desencadeadoras da aprendizagem, isso é importante porque levamos para 0 aluno uma nova visão de ensinar Matemática porque os alunos já estão acostumados em toda aula de Matemática ser sempre a mesma coisa, com o CluMat podemos aprender uma nova forma de ensinar Matemática" (Flash 5, Cena 1,). Moura (1992) mostra que um dos elementos da AOE é a situação de conflito ou desencadeadora da aprendizagem, pois tem como conteúdo o motivo que leva os sujeitos a novas ações e reflexões sobre o objeto de estudo. Assim, esse processo de organização do ensino possibilita que o professor se aproprie da cultura humana historicamente acumulada e, concomitante, reeduque e desenvolva seu próprio pensamento teórico.

No processo de constituir-se como professor é primordial que haja um ambiente apropriado, então o CluMat configura-se como "um ambiente para o desenvolvimento de atividades educativas que possibilitem a discussão dos mais variados aspectos dentro do meio educacional na busca de formar relações entre as componentes abstratas e concretas do conhecimento" (CEDRO e MOURA, 2007, p.40). Nesta cena procurou-se identificar as possibilidades de aprender e ensinar a partir da estrutura proposta no CluMat e, na próxima cena, analisar-se-á a importância da teoria como guia da atividade orientada para o ensino e constituição da aprendizagem docente.

Cena 2 - A experiência do desenvolvimento da SDA: a teoria como guia da atividade orientada para o ensino 
Constituição da cena: Esta cena possui partes de uma entrevista realizada com os professores em formaçãono CluMat posteriormente ao desenvolvimento das atividades na escola parceira. A cena está localizada novigésimo oitavo momento do experimento formativo. Fez-se a seguinte pergunta: Ao participar do desenvolvimento da tarefa de estudo sobre conceito de números como foi o impacto dessa experiência para sua formação como professor de Matemática? Mediante a pergunta temos as seguintes respostas dos alunos:

Aluno 01: Os alunos ficaram todos motivados e era uma atividade lúdica onde eles aprenderam matemáticade um jeito legal sem ser aquele método mecânico em que ele só aprende para fazer prova e depois esquece,então para a minha formação foi interessante porque mostra pra gente que a gente pode inovar, que o lúdiconão é somente para as pedagogas.

Aluno 02: Foi uma experiência diferente, para o aluno e para gente também que desenvolveu a atividade $e$ mostrou que a propor outra organização do ensino de matemática é importante e funciona realmente, (Flash 1).

Aluno 03: utilizar uma aula diferente, uma aula que puxa a atenção do aluno é importante e da resultados,eles se envolvem mais, tem mais curiosidades, gostaram de saber que a matemática surgiu através da necessidade do ser humano.

Aluno 04: Então eu pude participar do desenvolvimento da atividade, é como eu falei, os alunos ficaram encantados acho que eu nunca participei de uma aula de matemática em que os alunos estivessem tão interessados o que é difícil, é só conversa, e lá não, lá eles empenharam em resolver cada etapa, de procurare buscando mesmo, a gente não dava as respostas, deixávamos eles irem descobrindo as coisas.

Aluno 05: eu achei outra parte muito interessante do projeto é de não dar resposta para o aluno e deixar fazer essa atividade orientadora como Moura fala, para que 0 aluno através da atividade orientadora que teorienta a ir por um percurso que o próprio aluno vai chegar lá por conta própria sem o professor dar a resposta.

Aluno 06: Eu não sabia o que era números, não tinha a noção do porquê que o ser humano criou os números e quando eu tive contato com essa atividade a gente teve que se preparar para apresentar essa atividade em sala de aula, nós tivemos todo o aporte teórico, aprendemos o que era os números, como era estruturado, como que eles foram criados em diversas partes do mundo ao mesmo tempo, sendo que várias civilizações desenvolviam números e eles representavam quantidades com esses números, (Flash 2).

Aluno 07: a atividade era orientada de forma que os nexos internos do conceito de números fossem aprendidos e quando fomos para a sala de aula com essa $\mathrm{HQ}$ sabendo quais era os nexos do conceito de números, podemos perceber uma diferença enorme quando se ensina o número para uma criança de qualquer jeito eles aprendem o símbolo e não o significado, mas com a $\mathrm{HQ}$ eles aprenderam e se apropriaram do que tem na essência do conceito, pois pararam de observar os números apenas como símbolos, eles entenderam o sentido dos números, e isso só foi possível porque a atividade estava planejada para esse objetivo, (Flash 3).

Aluno 08: Fazendo parte dessa construção da $\mathrm{HQ}$ foi bom, porque aprendemos a planejar a atividade, a aula, baseando em uma teoria, em algo concreto que existe e que tenha comprovação, e no momento do estágio você não vê, porque no estágio ele te pede um plano de aula, então acaba sendo mais conteúdo, e dentro do Clube não, devido termos a parte teórica, assim levamos a aula para o campo de pesquisa e não só de ensinar, então projetos como esse o clube de matemática a gente desenvolve um tipo de pesquisa, então através de teoria buscar a comprovação e a efetivação do que queremos, (Flash 4).

Aluno 06: Essas atividades tem um impacto importante porque nós não tínhamos até então nenhum tipo de contato com atividades alicerçadas numa base teórica para se ensinar matemática, até mesmo durante a realização do estágio, nós chegamos na sala de aula e realizamos aulas tradicionais, elaboramos o plano de aula com exercícios retirados de livros didáticos e internet e sem a oportunidade do CluMat continuavam sendo tradicionais, então essa $\mathrm{HQ}$ é importante porque ela leva para o aluno uma atividade que foi orientada para conduzir o aluno a sua aprendizagem, ela é lúdica e divertida mas ela tem objetivo, tem orientação, não é perdida, tem uma meta que é ensinar o conceito matemático de números então acaba sendo importante para a formação do professor de matemática, (Flash 5).

Esta cena se sustenta na importância da teoria como guia da atividade de ensino. Acredita-se que o professor ao embasar teoricamente os elementos que estruturam suas ações de ensino tem melhores condições de organizar seu trabalho: "Foi uma experiência diferente, para o aluno e para gente também que desenvolveu a atividade e mostrou que ao propor outra organização do ensino de Matemática é importante e funciona realmente" (Flash 1, Cena 2,); "eu não sabia o que era números, não tinha a noção do porquê que o ser humano criou os números e 
quando eu tive contato com essa atividade a gente teve que se preparar para apresentar essa atividade em sala de aula, nós tivemos todo o aporte teórico, aprendemos o que era os números, como era estruturado, como que eles foram criados em diversas partes do mundo ao mesmo tempo, sendo que várias civilizações desenvolviam números e eles representavam quantidades com esses números" (Flash 2, Cena 2). Sobre o processo de apropriação do conhecimento e formação do indivíduo Leontiev (1978) explica que isso acontece a partir da apropriação dos fenômenos externos da cultura material e intelectual produzidos pela humanidade, e o processo de transmissão das aptidões humanas se deve à atividade fundamental e exclusivamente humana: o trabalho. Deste modo o professor não nasce professor, mas precisa aprender a ser, pois as características que o formam são constituídas historicamente e transmitidas de geração em geração, sendo as aptidões apreendidas nesse processo serão possíveis mediante o trabalho.

Nessa mesma perspectiva entender o trabalho como atividade principal do sujeito permite compreender que os mesmos se relacionam com a realidade que os circundam, transformando-a e transformando-se, possibilitando a internalização de determinados conhecimentos, ou seja, é um processo que acontece do social para o individual. Vygotsky(1993, p. 64) a respeito dessa relação afirma que "todas as funções no desenvolvimento humano aparecem duas vezes: primeiro, no nível social, e, depois, no nível individual; primeiro, entre pessoas (interpsicológica), e, depois, no interior da criança (intrapsicológica)". Diante disso, conhecer a teoria que embasa as ações do indivíduo nessa investigação sobre professores de Matemática em formação inicial leva-nos a tomar consciência de sua atividade.

Nessa mesma trajetória, pode-se observar a importância da teoria no processo de constituição da atividade do professor no seguinte flash: "A atividade era orientada de forma que os nexos internos do conceito de números fossem aprendidos e quando fomos para a sala de aula com essa $\mathrm{HQ}$ sabendo quais eram os nexos do conceito de números, podemos perceber uma diferença enorme quando se ensina o número para uma criança de qualquer jeito eles aprendem o símbolo e não o significado, mas com a HQ eles aprenderam e se apropriaram do que tem na essência do conceito, pois pararam de observar os números apenas como símbolos, eles entenderam o sentido dos números, e isso só foi possível porque a atividade estava planejada para esse objetivo" (Flash 3, Cena 2). Davidov (1998), ao elaborar suas teorizações a respeito do ensino para promover o desenvolvimento cognitivo, afirmou que para formação do pensamento teórico-científico, conforme a lógica dialética, é necessária a integração entre os conteúdos científicos e o desenvolvimento dos processos de pensamento, na busca de desenvolver-se como 
sujeito que organiza o ensino, sendo o conhecimento científico conteúdo da atividade de aprendizagem, e com base nesse conteúdo, que surgem os métodos para estruturar o ensino.

Nesse processo de estruturação da atividade de ensino provoca-se o movimento de mudança qualitativa ao estabelecer novas relações com a realidade objetiva, a qual parte da intencionalidade que busca romper com a necessidade imediata e cria condições para que os sujeitos se apropriem do conhecimento sócio-histórico. Deste modo, as ações de ensino planejadas permitem que se produza aprendizagem.

Diante disso, o professor em formação torna-se agente principal na atividade de ensino à medida que supera o senso comum na apropriação do conhecimento: "Fazendo parte dessa construção da $\mathrm{HQ}$ foi bom, porque aprendemos a planejar a atividade, a aula, baseando em uma teoria, em algo concreto que existe e que tenha comprovação, e no momento do estágio você não vê, porque no estágio ele te pede um plano de aula, então acaba sendo mais conteúdo, e dentro do Clube não, devido termos a parte teórica, assim levamos a aula para o campo de pesquisa e não só de ensinar, então projetos como esse o Clube de Matemática a gente desenvolve um tipo de pesquisa, então através de teoria busca a comprovação e a efetivação do que queremos" (Flash 4, Cena 2). Bernardes (2009) reforça que se a aprendizagem [produto] não for objetivada, plena ou parcialmente, não se pode considerar o ensino [instrumento] elemento mediador na produção dos objetos da atividade pedagógica. Assim, a atividade de ensino deve ocorrer de forma que assegure circunstâncias que favoreçam a aprendizagem de forma consciente para que o sujeito se aproprie verdadeiramente dos atributos essenciais do objeto de estudo.

O flash também nos remete à articulação entre teoria e prática na constituição da práxis como ação transformadora consciente, ou seja, o professor também se educa e se forma quando organiza o ensino (elenca conteúdos, elabora ações) e, nesse movimento, a transformação ocorre tanto nas ações do professor quanto na realidade escolar na qual está inserido.

Nesse processo em que o professor se apropria teoricamente dos elementos que estruturam suas ações de ensino Davidov (1998) corrobora que é necessário que o professor se aproprie de metodologias de ação e formas de agir facilitadoras do trabalho a partir da explicitação da atividade de ensinar. Nesse sentido temos o próximo flash: "Essas atividades tem um impacto importante porque nós não tínhamos até então nenhum tipo de contato com atividades alicerçadas numa base teórica para se ensinar Matemática, até mesmo durante a realização do estágio, nós chegamos na sala de aula e realizamos aulas tradicionais, elaboramos o plano de aula com exercícios retirados de livros didáticos e internet e sem a oportunidade do CluMat continuavam sendo tradicionais, então essa $\mathrm{HQ}$ é importante porque ela leva para o aluno uma atividade que 
foi orientada para conduzir o aluno a sua aprendizagem, ela é lúdica e divertida mas ela tem objetivo, tem orientação, não é perdida, tem uma meta que é ensinar o conceito matemático de números então acaba sendo importante para a formação do professor de Matemática" (Flash 5 , Cena 2). Para Davidov (1998), em relação à sua discussão teórica sobre o ensino, o professor deve estar no seio de sua atividade ao aliar conteúdo específico e domínio de habilidades e capacidades específicas do ato de ensinar. Deste modo, o flash também indica que a finalidade da atividade de ensino é garantir a aprendizagem do conhecimento científico que leve ao desenvolvimento das funções psíquicas superiores.

Não se pode ver o trabalho do professor como uma mera visão prática, pois quando admitido como práxis implica dominar aquilo que se realiza - planejamento e desenvolvimento guiado por uma teoria que possibilita antever o resultado que objetiva, permitindo avaliar 0 resultado de suas ações (MOURA, 2013). Deste modo, a análise identifica a relevância da teoria como guia da atividade orientada para o ensino e a importância da apropriação teórica para a constituição e desenvolvimento da atividade pedagógica.

\section{Considerações finais}

Pode-se observar que os sujeitos de pesquisa demonstraram uma mudança de sentidos em relação à formação docente a partir da elaboração de uma SDA. Deu-se importância ao planejamento intencional de suas ações e o papel da coletividade e da historicidade do conceito para tal feito e, foi com base na intencionalidade e organização de ações no CluMat, que houve indícios da constituição da atividade principal desses professores em formação, salientando 0 quão é relevante a apropriação conceitual permitida nesse espaço peculiar que é o Clube de Matemática.

Os dados deram sinais de transformações ocorridas no sentido atribuído por esses professores em relação à atividade docente. Deste modo a $\mathrm{AOE}$ configurou-se como instrumento mediador na aprendizagem docente e unificador da relação entre teoria e prática que leva os sujeitos à constituição de sua práxis como ação transformadora consciente.

Nessa perspectiva, expôs- se a necessidade da elaboração da SDA no processo formativo dos professores de Matemática. Ao pensar o ensino de Matemática com base nos pressupostos teóricos da Atividade Orientadora de Ensino foi possibilitado aos professores em formação inicial uma nova perspectiva para a maneira como pensam o ensino dos conceitos matemáticos e também o conhecimento de novos caminhos, a princípio não conhecido por eles. 
Neste artigo, o CluMat se apresenta aqui como uma possível garantia dessas condições. Lugar onde se possa de forma adequada e com tempo disponível para planejamento e estudos, realizar o planejamento de atividades em conformidade com as leis psicológicas do desenvolvimento humano (SILVA; SOUSA, 2019). Vemos no CluMat um espaço de possibilidades para repensarmos os problemas referentes ao ensino e aprendizagem da Matemática no Brasil. Porém, com a consciência de que manter um espaço de desenvolvimento contínuo da transformação social não é de longe uma tarefa fácil, mas que a "educação em geral é um órgão social capaz de satisfazer [esse] preceito" (MÉSZÁROS, 2008, p. 110). Consequentemente, a educação escolar, como parte da educação em geral, tem uma parcela de responsabilidade nesse processo, motivo pelo qual CluMat UEG - Quirinópolis não se encarcera nos muros da Universidade. Para tanto, faz-se necessário, superar os limites físicos entre escola e Universidade, para depois superar os da lógica formal no processo de ensino e aprendizagem dos conhecimentos matemáticos produzidos historicamente pela humanidade. Tal necessidade é geradora da necessidade da realização de novas pesquisas

\section{Referências}

BERNARDES, Maria ELiza Mattosinho. Ensino e aprendizagem como unidade dialética na atividade pedagógica. Psicologia Escolar e Educacional, São Paulo, 13, p. 235-242, 2009.

CEDRO, Wellington Lima (Org.). Clube de Matemática: vivências, experiências e reflexões. Curitiba: CRV, 2015.

CEDRO, Wellington Lima. 0 motivo e a atividade de aprendizagem do professor de matemática: uma perspectiva histórico-cultural. 2008.Tese (Doutorado em Educação) Faculdade de Educação, Universidade de São Paulo, São Paulo.

CEDRO, Wellington Lima. 0 espaço de aprendizagem e a atividade de ensino: 0 Clube de Matemática. 2004. Dissertação (Mestrado em Educação) - Faculdade de Educação, Universidade de São Paulo, São Paulo.

CEDRO, Wellington Lima; MOURA, Manoel Oriosvaldo de. Uma perspectiva histórico-cultural para o ensino de álgebra: o clube de matemática como espaço de aprendizagem. Zetetike, Campinas, 15(1), p. 37-56. 2007. Disponível em: https://doi.org/10.20396/zet.v15i27.8647015. Acesso em 10 mar. 2020.

DAVYDOV, V. V. Problemas do Ensino Desenvolvimental - A Experiência da Pesquisa Teórica e Experimental na Psicologia. Tradução de José Carlos Libâneo e Raquel A. M. da Madeira Freitas. 1988. Disponível em:

http://professor.ucg.br/SiteDocente/admin/arquivosUpload/5146/material/Davydov\%20Texto\%20c ompleto\%202009\%20jun.doc. Acesso em: 04 de jan. 2015. 
DAVIDOV, Vasili; MARKOVA, A. K. La concepción de la actividad de estudio en los escolares. In: SHUARE, Martha. La psicologia evolutiva em La URSS: Antologia. Móscu: Editorial Progreso, 1987.

DAVYDOV, Vasili. Tipos de generalización en la enseñanza. 3. ed. Habana: Pueblo y Educación, 1982.

FERREIRA, Cezar Augusto. A aprendizagem da docência em matemática a partir da elaboração de uma situação desencadeadora da aprendizagem. 2019. Dissertação (Mestrado em Educação em Ciências e Matemática) - Programa de Pós-graduação em Educação em Ciências e Matemática, Universidade Federal de Goiás, Goiânia, 2019.

KOPNIN, Pavel. A dialética como lógica e teoria do conhecimento. Rio de Janeiro: Civilização Brasileira, 1978.

LEONTIEV, Alexis. O desenvolvimento do psiquismo. Lisboa: Livros Horizonte, 1978.

LIBÂNEO, Jose Carlos. Pedagogia e pedagogos, para quê? São Paulo: Cortez, 1999.

LOPES, Anemari Roesler Luersen Vieira. Aprendizagem da docência em matemática: o Clube de Matemática como espaço de formação inicial de professores. Passo Fundo: Editora UPF, 2009.

MESZÁROS, Istvan. Educação para além do Capital. São Paulo: Boitempo, 2008.

MORAES, Silvia Pereira Gonzaga; MOURA, Manoel Oriosvaldo de. Avaliação do Processo de Ensino e Aprendizagem em Matemática: contribuições da teoria histórico-cultural. Bolema. Boletim de Educação Matemática, Rio Claro, v. 33, p. 97-116, 2009.

MORETTI, Vanessa Dias. Professores de matemática em atividade de ensino: uma perspectiva histórico-cultural para a formação docente. 2007. 206f. Tese (Doutorado em Educação: Ensino de Ciências e Matemática) - Faculdade de Educação, Universidade de São Paulo, São Paulo, 2007.

MOURA, Manoel Oriosvaldo de. A dimensão da alfabetização na educação matemática infantil. In: KISHIMOTO, T. M; OLIVEIRA-FORMOSINHO, J. (Orgs.). Em busca da pedagogia da infância: pertencer e participar. Porto Alegre: Penso, 2013, p. 110-135.

MOURA, Manoel Oriosvaldo de. Pesquisa colaborativa: um foco na ação formadora. In: BARBOSA, Raquel L. Leite (Org.). Trajetórias e perspectivas da formação de educadores. São Paulo: Unesp, 2004, p. 257-284.

MOURA, Manoel Oriosvaldo de. A atividade de ensino como ação formadora. In: CASTRO, Ana; CARVALHO, Ana Maria Pessoa de (Org.). Ensinar a ensinar: didática para a escola fundamental e média. São Paulo: Pioneira Thomson Learning, 2002, p.143-162.

MOURA, Manoel Oriosvaldo de. A atividade de ensino como unidade formadora. Bolema, Rio Claro, 12, p. 29-43, 1996.

MOURA, Manoel Oriosvaldo de. A construção do signo numérico em situação de ensino. Tese (Doutorado em Educação: Ensino de Ciências e Matemática - Faculdade de Educação, Universidade de São Paulo, São Paulo, 1992. 
MOURA, Manoel Oriosvaldo de, ARAÚJO, Elaine Sampaio, MORETTI, Vanessa Dias, PANOSSIAN, Maria Lucia, RIBEIRO, Flavia Dias, A Atividade Orientadora de Ensino Como Unidade Entre Ensino e Aprendizagem. In: MOURA, Manoel Oriosvaldo de (Org.) A atividade pedagógica na teoria histórico-cultural. Brasília, DF: Liber Livro, 2010.

OLIVEIRA, Daniela Cristina; CEDRO, Wellington Lima. O Ensino de Matemática nos Anos Iniciais: - Brincar e a Atividade de Estudo no Clube de Matemática. Revista Teoria e Pratica da Educação, Maringá - PR, v. 18, n.2, p. 41-54, Mai/Ago, 2015.

OLIVEIRA, Marta Kohl. Vygotsky: aprendizado e desenvolvimento, um processo sócio-histórico. 4. ed. São Paulo: Scipione, 2002.

RADFORD, Luis. Sobre Psicologia, Epistemologia Histórica e o Ensino da Matemática: Rumo a uma história sociocultural da Matemática. In: RADFORD, Luis. Cognição Matemática: História, Antropologia e Epistemologia. São Paulo: Ed. Livraria da Física, 2011.

RIGON, Algacir Jose; ASBAHR, Flavia. da Silva Ferreira; MORETTI, Vanessa Dias. Sobre o Processo de humanização. In: MOURA, Manoel Oriosvaldo de (Org.). A Atividade Pedagógica na Teoria Histórico- Cultural. Brasília: Líber, 2010, p. 13-44.

ROSA, Joselia Euzebio; MORAES, Silvia Pereira Gonzaga; CEDRO, Wellington Lima. A Formação do Pensamento Teórico em uma Atividade de Ensino de Matemática. In: MOURA, Manoel Oriosvaldo de. A atividade pedagógica na teoria histórico-cultural. Brasília: Liber livro. 2010, p. 135-154.

SÁNCHEZ VÁZQUEZ, Adolfo. Filosofia da práxis .2 ed. Rio de Janeiro: Paz e Terra, 1977.

SILVA, Maria Marta da. A apropriação dos aspectos constituintes da Atividade Pedagógica por professores de Matemática em formação inicial. Tese (Doutorado em Educação Ciências e Matemática) - Universidade Federal de Goiás, Goiânia, 2018.

SILVA, Maria Marta da; SOUZA, Roberto Barcelos. Formação Inicial De Professores De Matemática: O Clube De Matemática Como Espaço De Aprendizagem Da Docência. TEMPORIS [AÇÃO], Cidade de Goiás, v. 18, p. 49-70, 2019.

VYGOTSKY, Lev. Pensamento e linguagem. Tradução Jéferson Luiz Camargo; revisão técnica José Cipolla Neto. São Paulo: Martins Fontes, 1993. 